\title{
Application of DCT and Weld Harfacing for Enhancing Erosion Resistance of PCBN: A Review
}

\author{
Puneet Pal Singh $^{1}$, Pardeep Kumar ${ }^{2}$ and Gurpreet Singh ${ }^{3}$ \\ ${ }^{1 \& 3}$ Department of Mechanical Engineering, Punjabi University, Patiala, Punjab, India \\ ${ }^{2}$ Yadavindra College of Engineering, Punjabi University Guru Kashi Campus, Talwandi Sabo, Bathinda, Punjab, India \\ E-Mail: puneetsidhu12@gmail.com
}

\begin{abstract}
Solid particle erosion (SPE) is a dominating material removal process in various industries which contributes to material degradation of wide variety of engineering tools and components. Literature evidences the efforts made to capture the material degradation problem due to SPE. Enhancement of mechanical properties like hardness with sufficient ductility is prerequisite of erosion resistance. But it is difficult to improve conflicting properties such as hardness and ductility at the same time. Hardfacing is an effective method to extend the service life of machine components experiencing abrasive, corrosive or erosive wear, by increasing surface hardness without affecting the ductility of the base metal. It can be done with the help of various welding techniques, depending upon the prevailing conditions, requirements and desired results. Submerged arc welding (SAW) provides large deposit rates with ease of automation. Heat treatment is a conventional process, which is used since long times to alter different properties of materials according to the requirements. Deep cryogenic treatment (DCT) followed by a subsequent tempering process has also reported to produce interestingly positive results by improving hardness, toughness and erosive wear resistance of tool steels, carburized steels and cast irons. This paper reviews the current status of literature exhibiting the use of DCT in tackling the problem of SPE and its proposed use in improving erosion resistance of pulverized coal burner nozzles (PCBN's) used in thermal power generation plant.
\end{abstract}

Keywords: Solid Particle Erosion (SPE), Submerged Arc Welding (SAW), Deep Cryogenic Treatment (DCT), Retained Austenite, Pulverized Coal Burner Nozzle (PCBN)

\section{INTRODUCTION}

Particulate material has always been a fundamental premise for material degradation, be that helicopter engine operative in dust clouds, equipment in mining industry or transportation and handling of pulverized coal [1]. Although, coal particulates cause certain material removal of the parts below specific critical velocities, but their detrimental results can easily be recognized, in a short period of time, with a change in their direction of travel by as low as 10 degrees [2]. Pulverized coal used in thermal power plants, having high mass flux and velocity, strikes the pulverized coal burner nozzle (PCBN) at different angles has justified the excessive solid particle erosion (SPE) caused by the directional change mentioned in literature [2-4]. Solid particle erosion also sometimes referred as impact wear is the surface deformation as a result of material degradation caused by the impingement of the solid particles with some considerable velocity on target material [1].

Particle as well as material properties are responsible factors that influence SPE [4-6]. Erodent particle variables such as size, shape, kinetic energy, composition, hardness, friability and angle of impact have certain specific values as per prevailing conditions in the thermal power plant. Whereas, material intrinsic characteristics such as its microstructure, hardness, carbide volume fraction (CVF) [7] and mechanical properties are more prevalent factors that can be altered to augment erosion resistance as well as operative lifetime of a component [8] [5].

Hardfacing has been widely accepted as the most prudent technique for restoring the original state of the worn components damaged by frequent erosive wear [9-13]. It may be defined as durable protective layer homogeneously deposited on the base metal by using some suitable welding technique, to repair as well as to alter its tribological properties [14].

Conventional heat treatment methods are also used to modify microstructure of materials for improved erosion resistance. From the viewpoint of improving wear resistance of a component, cryo-treatments particularly deep cryogenic treatment (DCT) in coalescence with traditional heat treatment process had produced interestingly positive results in a number of cases [15-29]. The increase in amount of retained austenite has proved detrimental for steel components, as it gives rise to reduction in yield strength, tensile strength, compressive residual stress, fatigue resistance. Moreover, this soft and metastable phase [30] is more susceptible to erosion wear than martensite [2]. Tempering treatment may lower its composition in a matrix, but a considerable reduction in hardness and strength simultaneously, easily overwhelms its potential benefits [16]. Deep Cryogenic treatment is reported to be an effective technique for transformation of retained austenite into martensite, with enhanced hardness, improved microstructure and homogeneous carbide distribution and more carbide volume fraction (CVF) of a subjected component [17, 31]. It is mostly considered for the enhancement of wear resistance, either abrasive or erosive, preferably of tool steels [24-27, 31]. However, very rare work is reported on the cryogenic treatment of stainless 
steel, a material normally used for the manufacturing of PCBN's. Undoubtedly, cryogenically treated samples are reported to show improved wear resistance with enhancement of even $200 \%$ [15], but these improvements significantly varied from steel of one composition to another without showing any kind of fixed pattern. Thus, it might not be a good idea to extend benefits of DCT shown on one specific grade steel on another steel of different grade [26]. Due to higher amount of diversion in its results, more meticulous study of DCT is required to understand whether it can be applied to particular steel for better erosion resistance [32].

\section{SOLID PARTICLE EROSION}

Solid particle erosion may be defined as the surface deformation or degradation of the material due to the impingement of solid particles, on the target material having significant kinetic energy. Similarly, ASTM defined SPE as the progressive loss of material from a solid surface of the target, due to continued exposure to impacts by solid particles [3] Dimensionless erosion rate is equal to the ratio of weight loss of the target sample to the weight of the erodent particles [1]. Material removal during erosion can be calculated as per thefollowing [5]:

$\begin{aligned} & \text { Volume removal } \\ & \text { per second } \\ & (\mathrm{cm} 3 / \mathrm{s})\end{aligned}=\frac{\text { Mass removal per second }(\mathrm{g} / \mathrm{s})}{\text { Average density }(\mathrm{g} / \mathrm{cm} 3)}$
$\begin{aligned} & \text { Erosion } \\ & (\mathrm{cm} 3 / \mathrm{kg})\end{aligned}=\frac{\text { Volumetric removal per second }(\mathrm{cm} 3 / \mathrm{s})}{\text { Mass amounts of impact particles per second }}$

It has been firmly established by the past works, that the ductile materials exhibits maximum erosive wear at shallow angles of $20-30^{\circ}$ and brittle materials experience higher erosion rates near normal impact angles of $80-90^{\circ}$ [5]. Erosive wear results in the removal of material from the target material, either by ductile or brittle mechanism [4].

When the erodent particle strikes the target material at a constant indentation pressure, its initial kinetic energy is assumed to be equal to the work done at a particular depth. Each impact displaces the original material to form the indentation. However, material removal would only take place once it has undergone several cycles of plastic deformation or has become significantly work hardened [33].

\section{A. Hardfacing}

As it is often economical and faster to restore and repair older parts subjected to frequent erosive wear than to replace them by totally new ones [13], repairing techniques find wider applications [34]. Hardfacing is one of the most economical ways to restore worn away surface to its original state as a result of a firm bond between the base and the deposited metal [11]. It is a protective layer on the surface of a matrix [7] that is proved beneficial in improving the operative lifetime of the components subjected to severe erosive wear $[12,35]$. In this type of surface treatment, an alloy is deposited homogeneously onto the surface of a material known as substrate [12], to alter wear, surface and tribological properties [4] without effecting the bulk properties of a material [6, 9, 14]. Because of the availability of wider number of welding processes, it is considered as the most economical method amongst various harfacing methods [10]. Hardfacing method should be aimed at obtaining strong bond between the base metal matrix and the deposit with high deposition rate. This can be efficiently achieved by weld hardfacing with submerged arc welding process [11].

\section{B. Submerged Arc Welding (SAW)}

Submerged arc welding is an arc welding process in which the arc is generated between a base metal also known as substrate and a bare or cored solid metal consumable wire. Arc heat causes the melting of base metal surface and wire electrode. The arc is maintained in a molten flux cavity, which is protectively concealed by a blanket of granular and fusible flux. Hence, it ensures that the weld is free from atmospheric contamination [36]. For achieving better welding performance in terms of improved hardness, dilution and deposition rate, in a SAW process proper selection of parameters like welding speed, arc current, arc voltage, electrode stick-out is must [11]. Various advantages of SAW process are: large deposition rates, more than one wire can be used in the process simultaneously for weld metal deposition [36], operational simplicity, better surface finish [37], provides good strength [38], much lesser operator skills are required, Can be easily automated [39], ability to weld thick plates.

\section{Deep Cryogenic Treatment}

Cryogenic treatment or cold temperature treatment is known as freezing of subject materials by lowering their temperature to subzero temperature for a particular span of time [26]. It can be broadly classified into mainly two [20] or three categories depending upon the lowest temperature achieved during the respective treatment. The treatment is considered to be cold temperature treatment for $-50^{\circ} \mathrm{C}$ to $80^{\circ} \mathrm{C}$ temperatures, shallow cryogenic treatment for $-80^{\circ} \mathrm{C}$ to $-160^{\circ} \mathrm{C}$ temperatures and deep cryogenic treatment (DCT) for $-160^{\circ}$ to $-196^{\circ} \mathrm{C}$ temperatures respectively [21, 22]. Although all the above three treatments have been in use depending upon the results required, but according to reported results DCT can be considered superior of all. DCT may be defined as slow constant cooling of a component until a very low subzero temperature (ranging from $-160^{\circ} \mathrm{C}$ to $-196^{\circ} \mathrm{C}$ ), holding it at that temperature for a period of several hours and then gradually bringing it back to the room temperature $[18,40]$. A subsequent tempering may also be considered the part of this process, as only cooling 
down of the component to subzero temperatures is not sufficient to achieve desired results and full potential of DCT can only be achieved by addition of tempering process at the end [16-19]. For this reason DCT is not considered as a replacement of a heat treatment process, but it is an addon process to the conventional heat treatment $[20,25]$. The material subjected to DCT experiences a permanent change in its microstructure $[19,25,34]$.

As soaking temperature is related to the marteniste finish temperature of the material under consideration for a DCT process, thus optimization of DCT parameters is required depending upon the application [25] and chemical composition of the component [20]. Process parameters of a DCT are as follows: cooling rate (rate at which a component is cooled down to the required temperature), soaking temperature (minimum temperature attained during the DCT process), soaking or holding time (time period for which a component is held at lowest temperature achieved during a DCT process), tempering temperature (temperature of subsequent tempering process after DCT). A slow and constant cooling rate during a cryogenic process helps in reducing the temperature gradient within the component and lowers the stress [40]. It also avoids thermal shock damages and severe distortions [16-19].

Deep cryogenic treatment not only alters one, but many mechanical properties simultaneously and this has been attributed to one or more combination of the following factors: almost complete elimination or transformation of retained austenite into fresh martensite, precipitation of primary as well as secondary carbides, removal of residual stresses, enhancement of carbide population, better homogeneity of the hard phase in martensite matrix and size refinement of carbides. The saturation of martensite at subzero temperatures leads to lattice distortion, hence both alloying and carbon atoms migrate to the defects in the vicinity and segregate there, which contribute to the formation of fine carbides during subsequent tempering process [18].

A number of advantages of DCT had been reported in the past, which are as follows: Dimensional stability of the component [16-18], improved wear resistance [17, 19, 22], increased hardness and strength of the material [20], extended operative lifetime of tools $[15,16,29,31]$, provides stress reveling in high speed steel (HSS) and medium carbon steels $[16,32]$, permanently alters the properties of a material [18, 29, 31, 34], affects entire cross section of a component, hence superior to coatings [31], helps in achieving optimum ratio between conflicting properties like hardness and ductility [17, 21], improved fatigue life [41], uniform microstructure with carbide distribution more homogeneous $[17,20,31]$. These advantages have been successfully applied to increase the wear resistance and dimensional stability of die tools stamps, bearings and motor blocks. Power generation industries, gun barrels, valves, gears, motor racing parts and even surgical and musical instruments have been celebrating the potentials of DCT [22]. AISI M2 high speed tool steel is the most common material being subjected to cryogenic treatments [17].

\section{DISCUSSION}

Erosive wear is directly related to the balance between mechanical properties [5], microstructure including carbide volume fraction and distribution of hard phase in relatively soft matrix. Dominance of any one phase leads to typical ductile or typical brittle behavior of a material, which is detrimental for wear resistance in both the ways [42]. Cast iron hardfacings showed declining erosive wear resistance with harder alumina particles when size of the carbides was large in their matrix. Higher erosion rates can also be ascribed to relatively higher hardness values of erodents ranging from $856 \mathrm{Hv}$ to $1875 \mathrm{Hv}$ as compared to matrix hardness. Even the presence of primary carbides was not sufficient to resist erosive wear of the hardfacings [43]. Although, increase in wear reistant was experienced in past with an increase in hardness values, but no direct relation is established yet amongst the two properties [40]. However, it is also stressed that a ductile material exhibits better erosion resistance with an enhancement in its hardness [4].

Moreover, better resistance to penetration i.e. longer incubation periods are obtained in cold rolled specimen of AISI 316 which have better hardness as compared to the specimens which were not subjected to the cold rolling process [44]. Chromium content more than 10-12\% also leads to declining erosive wear and even at higher temperatures oxidiation had no significant effect in the erosive wear of metallic materials [1]. Stainless steels were more prone to SPE at shallow impact angles. Erosion rates also increased with rising tempertures and were almost double at $900^{\circ} \mathrm{C}$ testing temperature for $30^{\circ}$ impact angle $[3,5]$. It might have been due to the fact that in case of erosion at shallow angles, material with better elongation easily formed protrusions which were removed by successive impact of the alumina particles [5].

Optical micrographs and XRD analysis of SS304 hardfaced with commercial multi-carbide elecrode showed that the primary carbides in the austenite-carbide matrix were highly refined after the heat treatment process and this new microstructure formed significantly improved the erosion resistance of the specimen at oblique impact angles. Better erosion resistance is also ascribed to the even distribution of the fine hexagonal hard carbides in the matrix after the heat treatment [3].

Hardfacing layers of Fe-Cr-C and Fe-Cr-C-B alloys deposited on AISI 1020 steel substrate resulted in the dispersion of primary as well as hard secondary carbides in the relatively soft matrix. SEM results verified that in comparison to primary carbides, eutectic carbides formed were greater in number and much smaller in size with shorter mean distance between them [9]. Moreover, cases of improved hardness and wear resistance with an increased 
carbide volume fraction, are widely available in the literature.

Almost complete transformation of retained austenite into martensite takes place in heat treated HSS after DCT. Improved wear resistance of DCT specimens were reported not only because of extreme high of any of the one i.e. hardness or toughness. But a sufficiently high hardness along with moderately high toughness contributed to better wear resistance [15]. Transformation of retained austenite to newly formed martensite having greater c/a ratio as compared to the original martensite was observed in cryogenically treated En353 steel. Deep cryogenic treatment also causes the localized diffusion of carbon resulting in cluster formation. The freshly formed clusters acts as nuclei for the formation of ultra-fine carbides when tempering of cryogenically treated samples is done. The cryogenic treatment also leads to relaxation in every ultrafine domain of the matrix contributing to lower brittleness amongst samples as compared to other samples [16]. A bibliographic review on DCT [17] concluded that the enhancement in wear resistance of DCT components was due to the optimized ratio of hardness, strength and toughness of martensite matrix which in turn was ascribed by authors to mainly three factors i) almost complete transformation of the retained austenite into martensite [20], ii) promotion of precipitation of fine dispersed carbides, iii) removal of residual stress. However, it was also stressed that the increase in wear resistance of DCT components should be attributed mainly to fine dispersed carbide precipitation rather than just conversion of retained austenite to martensite that is reached in SCT also [17].

Deep cryogenic treatment not only facilitated an increase in carbide volume fraction of M2 HSS drills but also contributes in making carbide size as well as carbide distribution more homogeneous in the martensite matrix [17]. The most prevalent advantage of DCT is that it uniformly affects the entire area of cross section, thus augmenting the wear resistance throughout the component. Hence, this facet of cryogenic treatment makes it superior to any type of coating, as coatings only exist at few micron levels [18]. Deep cryogenic treatment specimens of AISI 420 stainless steel depicted homogeneous distribution of carbides as compared to untreated samples. The size of $70 \%$ of carbides in DCT samples was below $0.4 \mu \mathrm{m}$ accounting a diameter reduction of $145 \%$. Also the number of carbide particles below $1 \mu \mathrm{m}$ also improved significantly after DCT. An augmentation in hardness was contributed to higher strain state in the martensite, small secondary carbides precipitation, their finer distribution along the volume rather than transformation of retained austenite into martensite which can be achieved with other conventional heat treatment processes too. The study also reported an increase of $10 \%$ in impact toughness of samples after DCT [22]. HY-TUF steels also achieve greater strength because of the large difference between the micro-hardness of $\eta$-carbides and martensite (approximately $1269 \mathrm{Hv}$ ) after DCT [26]. In agreement with other studies, XRD patterns of AISI M2 tool steel also shows no peaks relating to retained austenite after DCT. Scanning electron microscope (SEM) analysis makes it evident that carbides are dispersed in the matrix more evenly and are much smaller in size and their precipitation also takes place near the grain boundaries [31]. Retained content in low carbon martensitic stainless steel was also reported to be very low i.e. $2.3 \%$ after DCT. The experimentation verified that the treatment made the martensite laths smaller and evenly distributed, thus contributing to modiefied microstructure, which in turn was responsible for enhanced hardness and dimensional stability [30].

The work done in [16] justified that low temperature treatment must be followed by a tempering process. Double DCT had no additional effect on the microstructure [21]. However, DCT done without subsequent tempering does not produce desirable results. While [20] stated that any of the one treatment either plasma nitriding or single tempering is necessary for stress relaxation after cryogenic treatment. A subsequent tempering after DCT process attributes to dimensional stability, reduction in residual stresses, increased ductility and toughness of the treated steel. In fact un-tempered DCT components showed a considerable rise in compressive residual stress from $125 \mathrm{Mpa}$ to $235 \mathrm{Mpa}$, whereas necessary tempering reduced the surface compressive residual stress to $80 \mathrm{MPa}[16,17]$. Deep cryogenic treatment also accelerates the diffusion driving force of carbon atoms which provides the formation of very fine carbides during tempering [30]. Tempering of M2 HSS drill in [24] at $200^{\circ} \mathrm{C}$ for 1 hour didn't only contributed in improved carbide precipitation but also released remaining stresses in the drill.

\section{CONCLUSION}

Solid particle erosion of PCBN is one of the most prevalent problem exisiting in every thermal power plant. Erosive wear is greatly influenced by the relative hardness of erodent particeles and target material. Heat treatment processes as well as number of customised alloy coatings can be applied from the available literature for the improvement of hardness of materials under erosive attcak. But loss in other properties like ductility and toughness is indigenous to an increase in hardness achieved by conventional heat treatment methods. While coatings may induce higher surface hardness without effecting the ductility of the subtrate metal, but coatings alone are not favourable in all the cases as they do not affect the entire cross section of the material and thus, are restricted only to few micron layers. Although, increased hardness has shown lesser erosive wear at shallow impact angles, but achievement of higher hardness to improve erosion resistance at the expense of significant decrease in ductility is not advisable in literature. A balanced combination of the two properties is required.

In addition to this, increase in retained austenite in steels leads to reduction in strength and hardness of the steel 
component. Moreover, facets like microstructure, carbide volume fraction, carbide size, appropriate distribution of hard and soft phases in a matrix and a certain amount of ductility also play a crucial role in overall erosive wear of stainless steels. It is hard to revamp all the factors along with combination of required balanced values by one single treatment.

Deep cryogenic treatment followed by a subsequent tempering is applied successfully in many of the case to attain all or some of the following (i) almost complete elimination of retained austenite, in some steels small traces of austenite lower than 3\% were also observed, (ii) precipitaion and refinement of carbides, (iii) increased hardness with suitable ductility, (iv) improved carbide distribution (v) better volume fraction of harder $\eta$-carbides, (vi) increased toughness. The amount of above mentioned benefits and magnitude of properties enhanced after a DCT process may vary from one steel to another, as the mechanism behind this process is not yet fully understood. However, interestingly positive results of DCT reported in the past had made it necessary to test its application on the stainless steels to check how far its potential benefits can go in curbing the problem of erosive wear in PCBN's. Dimensional stability and increased operative lifetime can already be seen in most of the tool steels, bearing steels and carburized steels.

\section{REFERENCES}

[1] M. Roy, "Elevated temperature erosive wear of metallic materials", Journal of Physics D: Applied Physics, Vol. 39, No. 6, pp. R101R124, 2006.

[2] G.A. Sargent, and D. Saigal, "Erosion of Low-Carbon Steel by Coal Particles", A S L E Transactions, Vol. 29, No. 2, pp. 256-266, 1986.

[3] B.S.S. Pardeep Kumar, "Heat Treatment Effect on Erosion Characteristics of Hypereutectic Structural Hardface Overlay", International Journal of Surface Engineering \& Materials Technology, Vol. 4, pp. 23-28, 2014.

[4] H.S.S. Chamkaur Jindal, "Erosion Resistance Behavior of SS304 Steel Hardfaced by SMAW with Addition of Molybdenum", Asian Review of Mechanical Engineering, Vol. 2, No. 2, pp. 61-65, 2013.

[5] K. Shimizu, Y. Xinba, and S. Araya, "Solid particle erosion and mechanical properties of stainless steels at elevated temperature", Wear, Vol. 271, No. 9-10, pp. 1357-1364, 2011.

[6] S.S.C. Anoop Monga, Wear of Materials- A Review. 2014.

[7] B. Venkatesh, K. Sriker, and V.S.V. Prabhakar, "Wear Characteristics of Hardfacing Alloys: State-of-the-art", Procedia Materials Science, Vol. 10, pp. 527-532, 2015.

[8] !!! INVALID CITATION !!!

[9] N. Yüksel, and S. Şahin, "Wear behavior-hardness-microstructure relation of $\mathrm{Fe}-\mathrm{Cr}-\mathrm{C}$ and $\mathrm{Fe}-\mathrm{Cr}-\mathrm{C}-\mathrm{B}$ based hardfacing alloys", Materials \& Design, Vol. 58, pp. 491-498, 2014.

[10] R. Zahiri, R. Sundaramoorthy, P. Lysz, and C. Subramanian, "Hardfacing using ferro-alloy powder mixtures by submerged arc welding", Surface and Coatings Technology, Vol. 260, pp. 220-229, 2014.

[11] Y.S. Tarng, and C.H. Chang, "Use of Grey Based Taguchi Methods to determine Submerged Arc Welding process parameters in Hardfacing", Journal of Materials Processing Technology, Vol. 128, pp. 1-6, 2002.

[12] M.F. Buchely, J.C. Gutierrez, L.M. León, and A. Toro, "The effect of microstructure on abrasive wear of hardfacing alloys", Wear, Vol. 259, No. 1-6, pp. 52-61, 2005.

[13] K. Weman, "Surface cladding and hardfacing methods", pp. 151-156, 2012.
[14] C. Katsich, E. Badisch, M. Roy, G.R. Heath, and F. Franek, "Erosive wear of hardfaced $\mathrm{Fe}-\mathrm{Cr}-\mathrm{C}$ alloys at elevated temperature", Wear, Vol. 267, No. 11, pp. 1856-1864, 2009.

[15] V. Leskovšek, M. Kalin, and J. Vižintin, "Influence of deepcryogenic treatment on wear resistance of vacuum heat-treated HSS", Vacuum, Vol. 80, No. 6, pp. 507-518. , 2006.

[16] A. Bensely, S. Venkatesh, D. Mohan Lal, G. Nagarajan, A.Rajadurai, and K. Junik, "Effect of cryogenic treatment on distribution of residual stress in case carburized En 353 steel", Materials Science and Engineering: A, Vol. 479, No. 1-2, pp. 229-235, 2008.

[17] C.D. P. Baldissera, "Deep Cryogenic Treatment: A Bibliographic Review", The Open Mechanical Engineering Journal, Vol. 2, No. 2008, pp. 1-11, 2008.

[18] V. Firouzdor, E. Nejati, and Khomamizadeh, "Effect of deep cryogenic treatment on wear resistance and tool life of M2 HSS drill”, Journal of Materials F. Processing Technology, Vol. 206, No. 1-3, pp. 467-472, 2008.

[19] J.D. Darwin, D. Mohan Lal, and G. Nagarajan, "Optimization of cryogenic treatment to maximize the wear resistance of $18 \% \mathrm{Cr}$ martensitic stainless steel by Taguchi method", Journal of Materials Processing Technology, Vol. 195, No. 1-3, pp. 241-247, 2008.

[20] B. Podgornik, F. Majdic, V. Leskovsek, and J. Vizintin, "Improving tribological properties of tool steels through combination of deepcryogenic treatment and plasma nitriding", Wear, Vol. 288, pp. 8893, 2012.

[21] S.E. Vahdat, S. Nategh, and S. Mirdamadi, "Microstructure and tensile properties of $45 \mathrm{WCrV} 7$ tool steel after deep cryogenic treatment", Materials Science and Engineering: A, Vol. 585, pp. 444454, 2013

[22] G. Prieto, J.E.P. Ipiña, and W.R. Tuckart, "Cryogenic treatments on AISI 420 stainless steel: Microstructure and mechanical properties", Materials Science and Engineering: A, Vol. 605, pp. 236-243, 2014.

[23] D. Senthilkumar, and I. Rajendran, "A research review on deep cryogenic treatment of steels", International Journal of Materials and Structural Integrity, Vol. 8, No. 1/2/3, pp. 169, 2014.

[24] S. Akincioğlu, H. Gökkaya, and İ. Uygur, "A review of cryogenic treatment on cutting tools", The International Journal of Advanced Manufacturing Technology, Vol. 78, No. 9-12, pp. 1609-1627, 2015.

[25] B. Podgornik, I. Paulin, B. Zajec, S. Jacobson, and V. Leskovšek, "Deep cryogenic treatment of tool steels", Journal of Materials Processing Technology, Vol. 229, pp. 398-406, 2016.

[26] A. Zare, and S.R. Hosseini, "Influence of soaking time in deep cryogenic treatment on the microstructure and mechanical properties of low-alloy medium-carbon HY-TUF steel", International Journal of Minerals, Metallurgy, and Materials, Vol. 23, No. 6, pp. 658-666, 2016.

[27] A. Zare, H. Mansouri, and S.R. Hosseini, "Influence of the holding time of the deep cryogenic treatment on the strain hardening behavior of HY-TUF steel", International Journal of Mechanical and Materials Engineering, Vol. 10, No. 1, 2015.

[28] K. Yildizlı, "Investigation on the microstructure and toughness properties of austenitic and duplex stainless steels weldments under cryogenic conditions", Materials \& Design, Vol. 77, pp. 83-94, 2015.

[29] G. Venses, and R. Sri Siva, "Optimisation of Deep Cryogenic Treatment Process on the Wear Resistance of 100Cr6 Bearing Steel using Taguchi technique", Journal of Advances in Mechanical Engineering and Science, Vol. 1, No. 2, pp. 9-20, 2015.

[30] S. Li, M. Xiao, G. Ye, K. Zhao, and M. Yang, "Effects of deep cryogenic treatment on microstructural evolution and alloy phases precipitation of a new low carbon martensitic stainless bearing steel during aging", Materials Science and Engineering: A, Vol. 732, pp. 167-177, 2018.

[31] S. Kumar, M. Nagraj, A. Bongale, and N. Khedkar, "Deep Cryogenic Treatment of AISI M2 Tool Steel and Optimisation of Its Wear Characteristics Using Taguchi's Approach", Arabian Journal for Science and Engineering, Vol. 43, No. 9, pp. 4917-4929, 2018.

[32] P. Baldissera, "Deep cryogenic treatment of AISI 302 stainless steel: Part I - Hardness and tensile properties", Materials \& Design, Vol. 31, No. 10, pp. 4725-4730, 2010.

[33] R.J.K. Wood, J.C. Walker, T.J. Harvey, S. Wang, and S.S. Rajahram, "Influence of microstructure on the erosion and erosion-corrosion characteristics of 316 stainless steel", Wear, Vol. 306, No. 1-2, pp. 254-262, 2013. 
[34] D. Das, A.K. Dutta, and K.K. Ray, "Sub-zero treatments of AISI D2 steel: Part II. Wear behavior", Materials Science and Engineering: A, Vol. 527, No. 9, pp. 2194-2206, 2010.

[35] K. Yang, Q. Yang, and Y. Bao, "Effect of carbonitride precipitates on the solid/liquid erosion behaviour of hardfacing alloy", Applied Surface Science, Vol. 284, pp. 540-544, 2013.

[36] B. Gülenç, and N. Kahraman, "Wear behaviour of bulldozer rollers welded using a submerged arc welding process", Materials \& Design, Vol. 24, No. 7, pp. 537-542, 2003.

[37] M.C. Carvalho, Y. Wang, J.A.S. Souza, E.M. Braga, and L. Li, "Characterization of phases and defects in chromium carbide overlays deposited by SAW process", Engineering Failure Analysis, Vol. 60, pp. 374-382, 2016.

[38] A. Arul, S.R.S.B. Marcel Moshi, R. Rajeshkumar, R. Kumar, "Factors Infulencing Submerged Arc Welding on Stainless steel- A Review", ARPN Journal of Engineeing and Applied Sciences, Vol. 11, No. 2, pp. 1237-1241, 2016.

[39] P.F. Mendez, N. Barnes, K. Bell, S.D. Borle, S.S. Gajapathi, S.D. Guest, H. Izadi, A.K. Gol, and G. Wood, "Welding processes for wear resistant overlays", Journal of Manufacturing Processes, Vol. 16, No. 1, pp. 4-25, 2014.

[40] J. Cui, and L. Chen, "Microstructure and abrasive wear resistance of an alloyed ductile iron subjected to deep cryogenic and austempering treatments", Journal of Materials Science \& Technology, Vol. 33, No. 12, pp. 1549-1554, 2017.

[41] P. Baldissera, and C. Delprete, "Deep cryogenic treatment of AISI 302 stainless steel: Part II - Fatigue and corrosion", Materials \& Design, Vol. 31, No. 10, pp. 4731-4737, 2010.

[42] A.V. Levy, "The Solid Particle Erosion Behavior of Steel as a Function of Microstructure", Wear, Vol. 68, pp. 269-287, 1981.

[43] S.G. Sapate, and A.V. Rama Rao, "Effect of carbide volume fraction on erosive wear behaviour of hardfacing cast irons", Wear, Vol. 256 No. 7-8, pp. 774-786, 2004.

[44] M. Divakar, V.K. Agarwal, and S.N. Singh, "Effect of the material surface hardness on the erosion of AISI316", Wear, Vol. 259, No. 16, pp. 110-117, 2005. 